of her bowel movements. Almost wholly disbarred from going into society, her misery during this period can readily be imagined.

On November 27, 1900, I operated, assisted by Drs. Charlton Wallace and J. W. D. Maury, her family physician, Dr. Stuart Close being present. 'The technic employed was one which in its simplicity and application seems hard to improve on. It was devised by Dr. Ristine of Knoxville, Tenn., more than twelve years ago and its technic was published by him some years afterward in the American Journal of Obstetrics and Diseases of Women. The details, accompanied by a rough sketch, which may serve better than words to make clear one or two steps, are as follows: The rectum being empty and cleansed, is packed with gauze. A horseshoe-shaped flap of mucous membrane, with its toe upward, is next outlined. The incision for this begins on either side of the vagina at the ends of the torn and retracted sphincter ani. The cut ascends on either side and meets at the toe, placed, in a case as bad as this, just as high as possible behind the cervix uteri-almost touching the cervix-so as to waste no length of flap that it is possible to secure. With a tear only dividing the sphincter, and not the rectum, obviously the horseshoe cut need not ascend so high.

The apron of the flap thus turned down will have its sound, $i$. e., its mucous membrane surface toward the feces and its raw surface forward. It will be dissected down as far as the upper end of the tear permits. If of proper length its lower or free ends should now hang as low as the anal level behind it. Any excess of length of this apron is a protection, for the time, to the dissected flesh in front against accidental infection, and if it should not finally shrivel, it can be snipped away.

Search is next made for the torn sphincter, the ends of which must be freshened and then brought into mutual apposition by means of tanned or chromicised catgut. The sphincter muscle, even in this case, could still be plainly recognized. By dissecting down and lengthening the horseshoe ends as needed, tissue is at length reached which when scized and pulled on by the forceps can be felt to draw the sphincter on either end. Before apposing these ends we should insert and tighten the continuous suture shown as $\mathrm{E}$ and $\mathrm{E}^{\prime}$ in the accompanying sketch. This helps to prevent any "dead space." The curved needle is inserted and brought out but four times in passing this stitch. Following the union of the sphincter the surgeon will probably perform the customary operation for torn perineum.

Before concluding, a moderate section of the sphincter at the rear anal margin should be made (in a case recently torn) to weaken it temporarily-for protection against the tearing out of the important stitches uniting its ends. Perhaps I need not say that in the case under discussion, after twenty-three years of disuse, it was thought unnecessary to weaken the sphincter further in this way. When this is done no stitch is taken; a clot fills the tiny opening made by the slender blade. The bowels are moved the second day and each day thereafter. Electricity and strychnin are of value in aiding the sphincter to recover its function.

I would refer those especially interested to the article by Dr. Charles G. Child, Jr., of this city, in the Journal of Obstetrics and Gynecology of the British Empire, July to December, 1905. It will be found that in a few particulars my operation differs from that of Dr. Ristine - the principle, however, is his, as also should be the entire credit of this, one of the very few operations which seem to me perfect in technic.

\section{APPENDECTOMY DURING HERNIOTOMY.}

\section{JOHN A. HAWKINS, M.D.}

Professor of Rectal Diseases in the Medical Department of the Western University of Pennsylvania; Rectal Surgeou to St. Francis Hospital. PITTSBURG, PA.

The article by Dr. John A. Wyeth, in The JournaL, Nov. 24, 1906, reminded me of two patients on whom I recently operated.

The first patient, a man of 67 , had suffered with a large inguinal hernia for many years. On opening the sac I found that it contained the cecum, the adherent appendix and part of the ileum. The appendix, though not inflamed, was removed, and the abdomen closed by the imbrication method of Fowler. Recovery was uneventful.

The second case was that of a woman of 62 , who suffered from an inflamed bubonocele. The sac contained a structure of whose identity I was not altogether certain until I had exam. ined it closely, but which proved to be the appendix. The constricted ring was incised and the hernia repaired by the Bassini method, the appendix being removed in the usual way. There was nothing unusual about the recovery. The appendix was $10 \mathrm{~cm}$. in length, $12 \mathrm{~mm}$. in diameter at the distal end and $4 \mathrm{~mm}$. at its attachment, being club-shaped.

219 Sixth Street.

\section{A CASE OF INFECTION BY STRONGYLOIDES INTESTINALIS.*}

\section{J. N. HALL, M.D.}

Visiting Physician to the Denver City and County Hospital. DENVER.

'This parasite, associated with Cochin-China diarrhea, has been reported so rarely in the United States that the following case should be recorded. The exact relationship to tropical diarrheas seems not definitely established:

Patient.-A Japanese ship's cook, aged 40, was admitted to my service in the Denver City and County Hospital, Oct. 18, 1906.

History. - We learned that he had visited many ports in Asia and other parts of the world, had been in America seven years, in Colorado three years. He had been sick for ten weeks, although below par for three or four months. He had a slight cough, had probably lost 20 or 30 pounds in weight, and was moderately anemic. He had five to eight stools in the twenty-four hours, mushy in consistence, foul smelling and of clay, slate or dark green color. No blood nor mucus. He complained of constant pain in the abdomen, and in the rectum on defecation. He vomited a few times, especially after eating sweet food.

Examination.-Physical examination of the chest and abdomen was negative. The urine was acid, sp. gr. 1030, a trace of albumin, no sugar, no bile, indican increased. A few small and narrow hyaline and granular casts, occasional blood cells and leucocytes. The examination of the sputum was negative. The blood, two weeks before death, showed: Hemoglobin (Tallquist), 65 per cent.; red cells, 3,200,000; white cells, 4,400. Moderate poikilocytosis and no megaloblasts nor normoblasts were found. A differential count of white cells showed polynuclear neutrophiles, 51.5 per cent.; lymphocytes, large and small, 47 per cent.; eosinophiles, .05 per cent. The absence of eosinophilia is to be noted.

Suspecting amebic dysentery, I asked Dr. B. B. Blotz, in charge of the laboratory, to examine the stools. His report is as follows:

"Larvæ of the Strongyloides intestinalis were found in great numbers. At least fifteen examinations were made and the parasite was present in each. An attempt was made to obtain the adult by incubating the larvæ for seventy-two hours at

* Reporter. with exhibition of specimens, to the Denver City and County Medical Society, No. 6, 1906. 
37-38 C. This was unsuccessful. At one examination a parasite was found having the same characteristics as the larvæ, but three times as long. The ova of the parasite were not discovered. Red blood cells and Charcot-Leyden crystals were found at various times. In the last two or three stools examined there were numerous black crystals, rhombic, quadrangular and needle shaped, probably of hematogenetic origin. These crystals were also found in the vomitus. A search was made for the ova of the ankylostoma duodenale, said to be often found in association with this parasite, but they were not discovered, nor could other ova be found. During the last few days the patient vomited several times in each twentyfour hours, and the parasites were abundant in the vomitus."

In every specimen of the fresh stools, mounted with water, under a power of $\mathbf{5 0}$ diameters, could be seen from five to thirty of the larvæ in active motion. After an hour or two, most of them became immobile, but could be resuscitated by adding more water and warming the slide slightly. The patient was fed on a liquid diet and given thymol in a dose of 15 grains three times a day. At the suggestion of Dr. Ralph Taylor, who had seen the parasite in his Philippine experience, 3 grains of santonin were added later. Although the parasites lost their activity, so that but one or two sluggish ones could be found in a field, with perhaps a dozen dead ones, the patient steadily lost ground, and died on Nov. 17, 1906. No autopsy could be obtained.

\section{RESPIRATION VALVES.}

C. C. GUTHRIE, M.D.

Professor of Physiology and Pharmacology, Washington University Medical School. sT. LouIs.

The valves shown in the accompanying drawing were designed primarily for use in preventing the waste of volatile anesthetics that commonly occurs in mammalian experiments when a Wollf's bottle is used in connection with a trachea tube and for simplifying the measurement of expired air in such experiments. Construction of plated brass with valve dises of aluminum, or of aluminum throughout, is satisfactory. An average of results from a test made on an $8 \mathrm{Kg}$. dog during a period of four hours is given below. The valves were not observed to stick or miss catching throughout the experiment.

1. Animal with tube in trachea breathing through a Wollf's bottle arrangement. Valves connected on the far side of the

Valve mechanism for laboratory experiments with respiration: IA, inspired air. EA, expired air. SC, spirometer connection. BC, bottle connection. TC, trachea connection. Sp, valve stop. D, valve disc. St, valve seat.

bottle in order to measure the volume of expired air. Volume of air measured by convey. ing it through a tube from the side branch to a spirometer.

2. Same arrangement as in 1, only the valves were inserted between the dog and bottle so that the expired air did not pass back through the bottle as in the first case.

\section{RESULrs.}

1. Amount of ether used per L. of air, 0.83 c.c.

2. Amount of ether used per L. of air, 0.42 c.c.

The average volume of expired air per minute was 3866 c.c. For simplicity calling it $4 \mathrm{~L}$., the amount of ether used per hour in 1 was 199.2 c.c., and in 2, 100.8 c.c.

The use of the valves also prevents contamination of the anesthetic contained in the bottle by condensation of moisture from the animal's breath.

\section{AN IMPROVED BEDSIDE CHARTHOLDER FOR HOSPITAL USE.}

\author{
J. D. SINGLEY, A.M., M.D. \\ Surgeon to the Pittsburg Hospital. \\ PITTSBurg, PA.
}

In this chartholder the back is a rigid light enameled metal plate. The clamp or clip is of heavy wire and has two contact points, but instead of relying on metal or small rubber tips at the contact points, as in those on the market, two rings come in contact with the back. Two upright pins about one inch high are set into the back over which the rings drop when the spring of the clamp is released. The record sheets, after padding, are perforated, at a very slight cost, by the printer at the proper place for the pins.

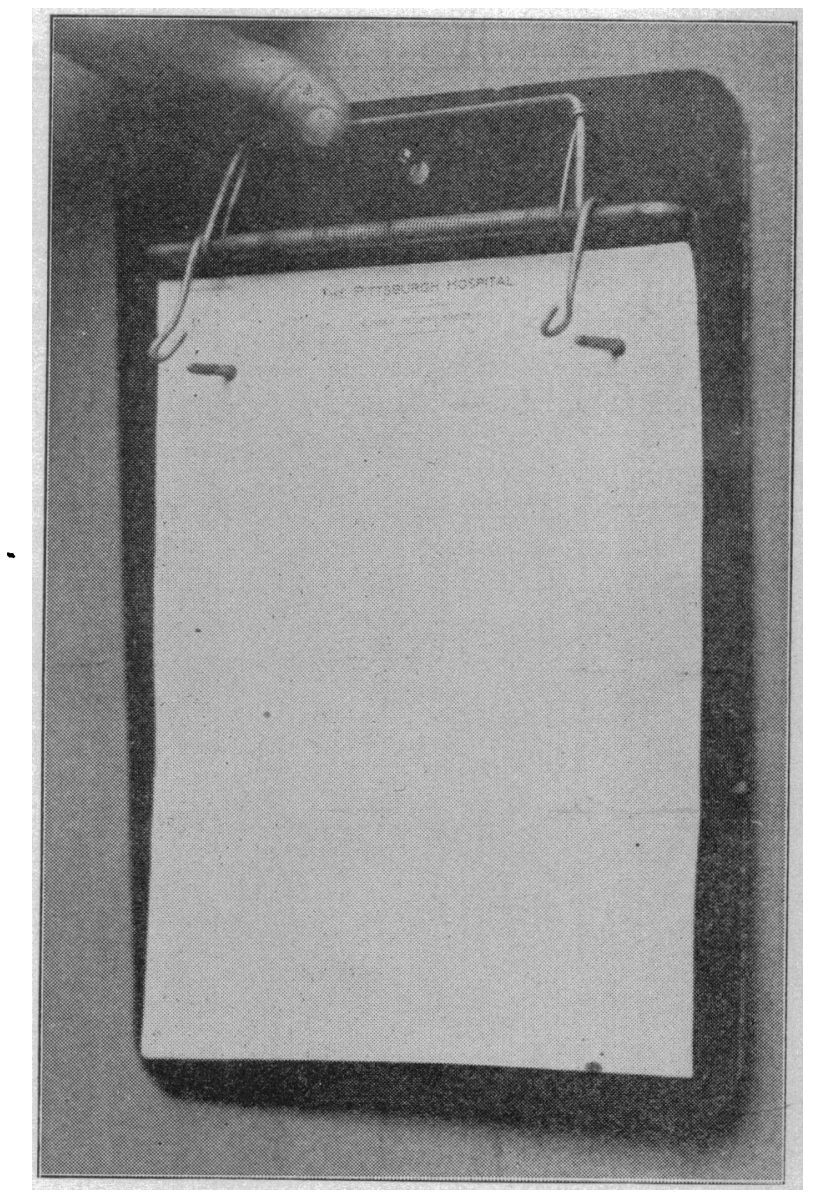

With such a holder the record sheets can only be released by exerting sufficient pressure to raise the ring of the clamp clear of the pin and lifting the sheets off the pin. No adjustment is required to keep the various sheets in alignment while the proper sequence of the sheets remains as originally placed.

812 North Highland Avenue.

Malaria and Tuberculosis.-P. Gracieux has been investigating conditions in tropical Africa and Mexico; he found malarial antecedents in 70 per cent. of the natives affected with tuberculosis. He believes that this malarial infection paves the way for tuberculosis later, and that it is absurd to claim that the native races are "peculiarly predisposed to tuberculosis." They have only unusual opportunities for malarial infection, and this is the cause for the prevalence of tuberculosis. His article opens the Cronica Med. Mexicana, for 1907. 